Western North American Naturalist 67(4), (C) 2007, pp. 609-610

\title{
DISCOVERY OF A LARGE POPULATION OF THE RARE WINTER STONEFLY ISOCAPNIA MOGILA RICKER IN THE MAD RIVER, CALIFORNIA (PLECOPTERA, CAPNIIDAE)
}

\author{
Richard W. Baumann ${ }^{1}$ and Jonathan J. Lee ${ }^{2}$
}

\begin{abstract}
Isocapnia mogila, a rare winter stonefly, is found in good numbers in Humboldt County, California. In the 50 years since this species was described, very few specimens were recorded from only 4 sites in California and Oregon. Emergence seems to be higher in the fall and early winter than in the late winter and spring.

Key words: winter stonefly, Isocapnia moglia, emergence.
\end{abstract}

The genus Isocapnia was erected by Banks (1938), studied by Ricker (1959), and recently revised by Zenger and Baumann (2004). The genus is 1 of the rarest genera in the family Capiidae in North America. Adult specimens are difficult to collect with any regularity, even by visiting known sites during subsequent years. However, nymphs can be obtained rather easily by pumping organisms from the hyporheic zone, as described in Stanford and Gaufin (1974).

Most winter stonefly collecting in the western United States takes place from January to May, with the best results usually coming in February. Since few records were known from the California Coast Range in the late fall, special efforts were made to sample some stonefly habitats in Humboldt County in late 2006 and early 2007. A positive result was the discovery of a good population of Isocapnia mogila Ricker in the Mad River, upriver from the Mad River Hatchery, Hatchery Road, near Blue Lake. This species was known up until this time from 2 localities in Oregon and 2 in California from a total of only 14 specimens. The male type specimen was collected in Douglas County, Oregon, on 22 November 1955; thus, over a 50year period very few specimens were found. Although the type was collected in November, the remaining specimens were recorded from January to March (Zenger and Baumann 2004). Consequently, it proved to be a good strategy to search for this species beginning in the fall of 2006.
The Mad River drains a $497-$ mile $^{2}$ watershed as it flows to the Pacific Ocean. Discharge data recorded near Arcata, California, from 15 November 2006 to 17 November 2006 ranged from 667 to 2690 cfs (USGS 2006), which suggested a medium-sized river. Using a beating sheet, we collected from sedge hillocks at the water's edge where the main flow was near the bank. The 1st adult specimens of $I$. mogila from the Mad River were collected on 15 November, with several more collected on 16 and 17 November. Multiple collections made approximately weekly yielded the following results:

15 November: 5 males, 1 female

16 November: 3 males, 4 females, 1 nymph

17 November: 16 males, 5 females

1 December: 2 females

19 December: 2 males, 2 females

29 December: 1 male

2 January: 1 male

8 January: 1 male, 1 female

17 January: 1 female

The last female adult was collected on 17 January 2007. Thus, the emergence period probably ended in January at this collecting site. The total emergence period recorded in this study extended from November 2006 to January 2007, with a total of 45 adult specimens collected. However, low rainfall in January created clear river conditions and increased steelhead fishing activity at the collecting site.

\footnotetext{
${ }^{1}$ Monte L. Bean Life Science Museum and Department of Integrative Biology, Brigham Young University, Provo, UT 84602. E-mail: richard_baumann@ byu.edu

22337 15th Street, Eureka, CA 95501.
} 
This activity hampered additional intensive collecting and could have altered our confirmation of the end of the emergence period.

Specimens obtained in this study are deposited in the following collections: Monte L. Bean Life Science Museum, Brigham Young University, Provo, Utah; C.P. Gillette Collection, Colorado State University, Fort Collins, Colorado; and Jonathan Lee Collection, Eureka, California. We give special thanks to our colleagues Bill Stark at Mississippi College and Boris Kondratieff at Colorado State University for their encouragement and help with this paper.

\section{Literature Cited}

Banks, N. 1938. New native neuropteroid insects. Psyche 45:72-79.
Ricker, W.E. 1959. The species of Isocapnia Banks (Insecta, Plecoptera, Nemouridae). Canadian Journal of Zoology 37:639-653.

Stanford, J.A., and A.R. Gaufin. 1974. Hyporheic communities of two Montana rivers. Science 185:700-702.

[USGS] United States Geological Survey. 2006. U.S. Geological Survey River Flow Stations. Available from: http://cdec.water.ca.gov/misc/usgs_ids.html

Zenger, J.T., and R.W. Baumann. 2004. The Holarctic winter stonefly genus Isocapnia, with an emphasis on the North American fauna (Plecoptera: Capniidae). Monographs of the Western North American Naturalist 2:65-95.

Received 9 February 2007 Accepted 14 May 2007 